\title{
A ReVista SMAD EM SEU OITAVo ANo de EXISTÊnCIA VEM APRESENTAR SEU NOVO FASCÍ́CULO - O DE NÚMERO 2
}

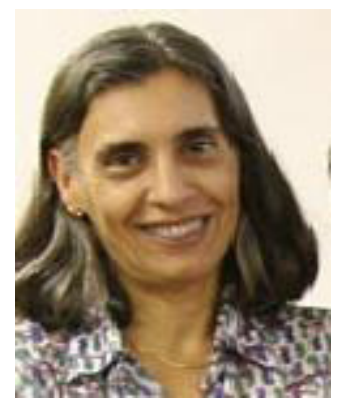

Ao final do ano 2012, a revista sofreu alterações importantes na composição de seu corpo editorial e, também, na forma de tramitação do processo de submissão de artigos. Iniciou-se, assim, em 2013, uma nova dinâmica em que tudo ocorre no interior do sistema que administra a revista. Não se tem mais o envio de artigos por e-mail assim como os pareceres. Dessa maneira, os autores podem acompanhar o processo de submissão de forma independente, sem precisar entrar em contato telefônico ou por e-mail.

Esse é um marco importante para um periódico que pretende avançar nos patamares de qualidade e abrangência.

Há ainda, no entanto, desafios postos para a comissão editorial da revista, visto que a entrada de artigos para avaliação é grande e o processo de avaliação ainda é lento. Destaco três grandes desafios para atingir um patamar de agilidade mais aceitável. O primeiro é angariar pesquisadores que possam atuar efetivamente na tarefa de emitir pareceres ad hoc. Embora nosso quadro de consultores seja amplo, acredito que o crescente envolvimento desses pesquisadores docentes em suas atividades cotidianas dificulte a aceitação de mais uma tarefa que demanda tempo. O segundo desafio é dar visibilidade a esse trabalho, além do que é feito hoje. Não tenho uma sugestão concreta, mas é preciso pensar sobre isso. E, por último, mas, talvez, o mais importante e decorrente dos dois anteriores é colocar a revista em dia. Os números publicados no corrente ano referem-se ao ano 2012.

O número atual traz artigos que visam apoiar o processo de formação do profissional enfermeiro para atuação na área de Saúde Mental. Sob esse tema destaco os trabalhos - RELAÇÃO DE AJUDA COM PACIENTE PSIQUIÁTRICO: ALÉM DO PARADIGMA MÉDICO, das autoras Renata Marques de Oliveira e Antonia Regina Ferreira Furegato e $O$ ENFERMEIRO E A EDUCAÇÃO EM SAÚDE MENTAL NA ATENÇÃO PRIMÁRIA: REVISÃO INTEGRATIVA, dos autores Fernanda Ribeiro Sobral e Claudinei José Gomes Campos. O primeiro oferece relato reflexivo sobre a assistência e como o profissional se posiciona na interação com uma pessoa com o diagnóstico de esquizofrenia. O outro trabalho trata de revisão de literatura sobre o trabalho em Saúde Mental na atenção primária à saúde. Ainda com foco mais destacado sobre os profissionais, há o trabalho com alunos de enfermagem e o cuidado com sua saúde mental - CUIDAR E SER CUIDADO: A OPINIÃO DE ACADÊMICOS DE ENFERMAGEM SOBRE UM PROJETO DE SAÚDE MENTAL, dos autores Marcelle Paiano, Beatriz de Carvalho Ciaciare, Maria Angélica Pagliarini Waidman, Lílian Cristina Bento e Bruna da Costa.

Outra categoria de artigos refere-se ao mapeamento de características psicossociais de usuários de serviços de assistência, voltados para o problema do uso abusivo de substâncias psicoativas. Dois artigos tratam dessa temática RESULTADOS DO ACOMPANHAMENTO DOS USUÁRIOS DO CENTRO DE ATENÇÃO PSICOSSOCIAL - ÁLCOOL E DROGAS (Caps - AD), dos autores Rivelilson Mendes de Freitas, Helen Rute Rodrigues da Silva e Diego Santos de Araújo e ALCOOLISMO NA REGIÃO CENTRO-OESTE DE MINAS GERAIS: PERFIL SOCIODEMOGRÁFICO, CLÍNICO E DISTRIBUIÇÃO GEOGRÁFICA, dos autores Richardson Miranda e Moacyr Lobo da Costa Júnior.

Uma terceira categoria reúne dois artigos que investigam o uso de tabaco em específico e de drogas lícitas e ilícitas em estudantes universitários. Esses dois trabalhos oferecem informações que podem ser utilizadas no manejo do problema de consumo de drogas entre jovens. São eles - USO DO TABACO ENTRE ESTUDANTES DE ENFERMAGEM DE UMA FACULDADE PRIVADA, dos autores Bruno Pereira, Carolina Maia Martins Sales, Marilene Gonçalves França e Marluce 
Miguel de Siqueira e INVESTIGAÇÃO DO USO DE DROGAS LÍCITAS E ILÍCITAS ENTRE OS UNIVERSITÁRIOS DE INSTITUIÇÕES DO ENSINO SUPERIOR (PÚBLICAS E PRIVADAS) NO MUNICÍPIO DE PICOS, PIAUIÍ, dos autores Rivelilson Mendes de Freitas, Danelle da Silva Nascimento e Pauline Sousa dos Santos.

Convido os leitores a visitarem mais este número da SMAD. Boa leitura!

Ana Maria Pimenta Carvalho é co-editora da SMAD, Revista Eletrônica Saúde Mental Álcool e Drogas, e Professor Associado da Escola de Enfermagem de Ribeirão Preto, Universidade de São Paulo, Centro Colaborador da OMS para o Desenvolvimento da Pesquisa em Enfermagem, Brazil, e-mail: anacar@eerp.usp.br. 